\title{
When the brain goes diving: transcriptome analysis reveals a reduced aerobic energy metabolism and increased stress proteins in the seal brain
}

\author{
Andrej Fabrizius ${ }^{1 \dagger}$, Mariana Leivas Müller Hoff $^{1 \dagger}$, Gerhard Engler², Lars P. Folkow ${ }^{3}$ and Thorsten Burmester ${ }^{*}$
}

\begin{abstract}
Background: During long dives, the brain of whales and seals experiences a reduced supply of oxygen (hypoxia). The brain neurons of the hooded seal (Cystophora cristata) are more tolerant towards low-oxygen conditions than those of mice, and also better survive other hypoxia-related stress conditions like a reduction in glucose supply and high concentrations of lactate. Little is known about the molecular mechanisms that support the hypoxia tolerance of the diving brain.

Results: Here we employed RNA-seq to approach the molecular basis of the unusual stress tolerance of the seal brain. An Illumina-generated transcriptome of the visual cortex of the hooded seal was compared with that of the ferret (Mustela putorius furo), which served as a terrestrial relative. Gene ontology analyses showed a significant enrichment of transcripts related to translation and aerobic energy production in the ferret but not in the seal brain. Clusterin, an extracellular chaperone, is the most highly expressed gene in the seal brain and fourfold higher than in the ferret or any other mammalian brain transcriptome. The largest difference was found for S100B, a calcium-binding stress protein with pleiotropic function, which was 38-fold enriched in the seal brain. Notably, significant enrichment of S100B mRNA was also found in the transcriptomes of whale brains, but not in the brains of terrestrial mammals.

Conclusion: Comparative transcriptomics indicates a lower aerobic capacity of the seal brain, which may be interpreted as a general energy saving strategy. Elevated expression of stress-related genes, such as clusterin and S100B, possibly contributes to the remarkable hypoxia tolerance of the brain of the hooded seal. Moreover, high levels of S100B that possibly protect the brain appear to be the result of the convergent adaptation of diving mammals.
\end{abstract}

Keywords: Brain, Calcium, Diving, Glucose, Hypoxia, Hooded seal, Marine mammals, Stress

\section{Background}

A shortage in the supply of oxygen (hypoxia) usually has a devastating impact on the function and the survival of the mammalian brain. Hypoxia is also involved in and is the cause of many neuronal disorders in humans, for example, Alzheimer's disease [1], Parkinson's disease [2] and cerebral ischaemia (stroke) [3-5]. A lack of oxygen

\footnotetext{
* Correspondence: thorsten.burmester@uni-hamburg.de

${ }^{\dagger}$ Equal contributors

${ }^{1}$ Institute of Zoology, Biocenter Grindel, University of Hamburg,

Martin-Luther-King-Platz 3, D-20146 Hamburg, Germany

Full list of author information is available at the end of the article
}

usually results in irreversible damage to the brain within few minutes and, eventually, death [4]. By contrast, the brain of diving mammals, i.e. whales and seals, may survive recurrent and extended periods of systemic hypoxia without damage [6-12].

The remarkable dive capacity of many marine mammals is brought about by a combination of various behavioural, anatomical and physiological adaptations [7-10, 13-16]. These adaptations that enhance $\mathrm{O}_{2}$ supply comprise high levels of haemoglobin and myoglobin, a large blood volume, increased blood stores, an enhanced capacity for 
anaerobic metabolism and resource-conserving cardiovascular adjustments such as bradycardia and peripheral vasoconstriction [11, 15, 17, 18]. In addition, marine mammals display particular adaptations to swimming, to coping with exposure to a hyperbaric environment, to thermoregulation in cold water, towards enhanced water conservation, and also show adaptations of the sensory organs $[15,19,20]$.

The hooded seal (C. cristata) displays an astonishing diving capacity, with a maximum dive duration of close to $1 \mathrm{~h}$ and a maximum recorded depth of $>1,000 \mathrm{~m}$ [21]. During the dive, the arterial blood $P_{2}$ drops dramatically, as also shown for some other deep-diving species $[6,12,17,22]$, and thus the seal brain has to deal with long periods of reduced $\mathrm{O}_{2}$ supply. Electrophysiological studies using brain slices demonstrated that the neurons of the hooded seal remained active under severe hypoxia and persisted up to $1 \mathrm{~h}$ while the neurons from mice died after only a few minutes [23, 24]. The brain of the hooded seal tolerates low glucose or high lactate levels, in normoxia as well as under hypoxia [25]. The hypoxia tolerance of the neurons of the hooded seal may be at least partly due to a shift of the oxidative metabolism from the neurons to the astrocytes, as evident from a distinct difference in the distribution of neuroglobin and cytochrome $\mathrm{c}$ in the brain of the hooded seal compared to the brains of terrestrial mammals [26, 27].

The adaptation of marine mammals to hypoxia on the genetic level may be partly explained by selective gene duplications and losses [28], or specific substitutions within the coding sequences [29]. However, there is little doubt that changes in the expression of individual genes also contribute to the adaptation. To better understand the molecular basis of the stress tolerance of the hooded seal brain, we have employed an RNA-seq approach and compared the abundances of transcripts in the visual cortex of the hooded seal and the ferret. We found that the brain of the hooded seal expresses fewer genes related to energy metabolism and translation, but showed remarkable levels of two typical stress genes, clusterin and S100B. Notably, a high expression level of S100B was also found in whales, but not in terrestrial mammals.

\section{Results}

Transcriptomes of the visual cortices of the hooded seal and the ferret

We obtained the transcriptomes from the visual cortex of the hooded seal and the ferret (see Additional file 1: Table S1 and Additional file 2: Table S2), mRNA expression levels were estimated by RNA-seq. A total of 10,298 transcripts had RPKM values $>1$ in both transcriptomes. For further analyses of differential expression, only transcripts with at least RPKM $>5$ in both species were considered, resulting in 6,229 transcripts (Additional file 3: Spreadsheet S1).
The highest mRNA levels in the visual cortex of the hooded seal (Table 1a) were found for the chaperone clusterin (CLU) with 3104.57 RPKM, followed by the neuromodulator prostaglandin D2 synthase (PTGDS; 2213.95 RPKM), the S100 calcium binding protein B (S100B; 1860.29 RPKM), a stress protein with pleiotropic function, the metabolic enzyme glyceraldehyde-3-phosphate dehydrogenase (GAPDH, 1413.17 RPKM) and the hydrolyzing enzyme glycerophosphodiester phosphodiesterase domain containing 2 (GDPD2; 1334.93 RPKM). In the brain of the ferret (Table 1b), the highest levels were found for GAPDH (3728.00 RPKM), the mitochondrially encoded cytochrome C oxidase II (MTCO2; 2266.01 RPKM), a peptidyl-prolyl cis-trans isomerase E-like gene (LOC101679695; 1824.67 RPKM) that catalyzes the isomerization of proline peptide bonds, and calmodulin 1 (1805.51 RPKM) and 2 (1802.73 RPKM), which both mediate the control of various enzymes and other proteins via $\mathrm{Ca}^{2+}$.

The largest differences between the expression levels in the hooded seal and the ferret brain (Table 2) were found for S100B, which has 37.98 times higher RPKM in the seal brain. The leucine-rich proteoglycan osteoglycin (OGN) was 12.14 times higher in the seal brain, followed by Nei endonuclease VIII-like 2 (NEIL2), a DNA glycosylase involved in the repair of damaged DNA $(10.11 \times$ higher in seal brain), the alcohol dehydrogenase hydroxysteroid (17-beta) dehydrogenase 11 (HSD17B11; $6.46 \times$ ), a transcript that encodes a serum protein associated with major histocompatibility complex $(\mathrm{MHC})$ class I proteins (beta-2-microglobulin; B2M; $6.26 \times)$, cytochrome P450, family 4, subfamily V, polypeptide 2 (CYP4V2; $6.05 \times)$ that oxidises fatty acids, and the antioxidant gene paraoxonase 2 (PON2).

\section{Functional annotation of transcripts differentially expressed in seal and ferret transcriptomes}

For GO analyses (Fig. 1), only genes with RPKM $>5$ in either species (6,229 genes; Additional file 3: Spreadsheet S1) and $>$ twofold expression difference were considered. In the genes (263 with Fold Change $>2$ ) that are more highly expressed in the seal brain, the GO terms "catalytic activity" (91) and "binding" (72) were the highest in the domain "molecular function" (Additional file 4: Table S3). The PANTHER overrepresentation test showed that the enrichment of the GO-Slim terms "structural constituent of cytoskeleton" (2.66-fold; $p=0.00644)$, "oxidoreductase activity" (2.56-fold; $p=0.0241)$ and "catalytic activity" (1.4fold; $p=0.0364$ ) was significant. The terms related to DNA-binding were underrepresented. In the domain "biological process", the highest numbers were allocated to the GO terms "metabolic process" (115) and "cellular process" (101). A large number of GO terms were found overrepresented, including terms related to glial cells ( $>5$-fold; $p<$ $0.05)$, "oxidation-reduction process" (2.48-fold; $p=0.0203$ ) and "response to stress" (1.73-fold; $p=0.00221$ ). In the 
Table 1 Most highly expressed genes in the visual cortex of the hooded seal (A) and ferret (B)

\begin{tabular}{|c|c|c|c|c|c|}
\hline Gene & Gene symbol & Function & Hooded seal (RPKM) & Ferret (RPKM) & Fold difference \\
\hline \multicolumn{6}{|l|}{ A. Hooded seal } \\
\hline Clusterin & CLU & Chaperone & 3104.57 & 777.62 & 3.99 \\
\hline Prostaglandin D2 synthase & PTGDS & Neuromodulator & 2213.95 & 1451.49 & 1.53 \\
\hline S100 calcium binding protein B & S100B & $\mathrm{Ca}^{2+}$-binding regulator & 1860.29 & 48.98 & 37.98 \\
\hline Glyceraldehyde-3-phosphate dehydrogenase & GAPDH & Metabolic enzyme & 1413.17 & 3728.00 & -2.64 \\
\hline $\begin{array}{l}\text { Glycerophosphodiester phosphodiesterase } \\
\text { domain containing } 2\end{array}$ & GDPD2 & Lipid metabolism & 1334.93 & 277.95 & 4.80 \\
\hline Glutamate-ammonia ligase & GLUL & pH control, removal of ammonia and L-glutamate & 1046.64 & 768.49 & 1.36 \\
\hline Calmodulin 2 & CALM2 & $\mathrm{Ca}^{2+}$-binding regulator & 1002.24 & 1805.51 & -1.80 \\
\hline SPARC-like 1 (hevin) & SPARCL1 & $\mathrm{Ca}^{2+}$-binding & 938.95 & 536.88 & 1.75 \\
\hline Aldolase C, fructose-bisphosphate & ALDOC & Metabolic enzyme & 918.67 & 906.26 & 1.01 \\
\hline Prosaposin & PSAP & Lipid metabolism & 883.57 & 913.66 & -1.03 \\
\hline \multicolumn{6}{|l|}{ B. Ferret } \\
\hline Glyceraldehyde-3-phosphate dehydrogenase & GAPDH & Metabolic enzyme & 1413.17 & 3728.00 & -2.64 \\
\hline Mitochondrially Encoded Cytochrome C Oxidase II & MTCO2 & Respiratory chain & 245.64 & 2266.01 & -9.22 \\
\hline Peptidyl-prolyl cis-trans isomerase E-like & LOC101679695 & Unknown & 98.39 & 1824.67 & -18.55 \\
\hline Calmodulin 2 & CALM2 & $\mathrm{Ca}^{2+}$-binding regulator & 1002.24 & 1805.51 & -1.80 \\
\hline Calmodulin 1 & CALM1 & $\mathrm{Ca}^{2+}$-binding regulator & 480.64 & 1802.73 & -3.75 \\
\hline Prostaglandin D2 synthase & PTGDS & Neuromodulator & 2213.95 & 1451.49 & 1.53 \\
\hline Mitochondrial ATP synthase, Beta subunit & ATP5B & Respiratory chain & 541.42 & 1166.96 & -2.16 \\
\hline Lactate dehydrogenase B & LDHB & Metabolic enzyme & 453.40 & 1127.78 & -2.49 \\
\hline Malate Dehydrogenase 1, NAD & $\mathrm{MDH} 1$ & Metabolic enzyme & 544.42 & 1055.62 & -1.94 \\
\hline Ribosomal protein L26 & RPL26 & Translation & 289.61 & 1040.08 & -3.59 \\
\hline
\end{tabular}


Table 2 Transcripts most highly overrepresented in the seal visual cortex compared to the ferret brain

\begin{tabular}{|c|c|c|c|c|c|}
\hline Differentially expressed gene & Gene symbol & Function & Hooded seal (RPKM) & Ferret (RPKM) & Fold difference \\
\hline S100 calcium binding protein B & S100B & $\mathrm{Ca}^{2+}$-binding regulator & 1860.3 & 49.0 & 37.98 \\
\hline Osteoglycin & OGN & Growth factor & 288.0 & 23.7 & 12.14 \\
\hline Nei endonuclease VIII-like 2 & NEIL2 & DNA repair & 51.1 & 5.1 & 10.11 \\
\hline Hydroxysteroid (17-beta) dehydrogenase 11 & HSD17B11 & Steroid synthesis & 81.3 & 12.6 & 6.46 \\
\hline$\beta$-2-microglobulin & B2M & Immune protein & 242.1 & 38.7 & 6.26 \\
\hline $\begin{array}{l}\text { Cytochrome P450, family 4, subfamily V, } \\
\text { polypeptide } 2\end{array}$ & CYP4V2 & Lipid metabolism & 86.2 & 14.3 & 6.05 \\
\hline Paraoxonase 2 & PON2 & Antioxidant protein & 95.9 & 17.3 & 5.54 \\
\hline Biglycan & BGN & Development and regeneration & 41.1 & 7.7 & 5.35 \\
\hline Moesin & MSN & $\begin{array}{l}\text { Membrane- cytoskeleton } \\
\text { interaction }\end{array}$ & 60.4 & 11.3 & 5.33 \\
\hline Transmembrane $4 \mathrm{~L}$ six family member 1 & TM4SF1 & Signal transduction & 33.4 & 6.3 & 5.31 \\
\hline
\end{tabular}

Only genes with RPKM values $>5$ were considered. Putative HLA-DRA genes were excluded

domain "protein class", the highest numbers were found in the terms "receptor", "cytoskeletal protein", "enzyme modulator", "hydrolase", "transferase", "nucleic acid binding", "transporter", and "oxidoreductase". The overrepresentation test showed significant enrichment of terms "actin family cytoskeletal protein" (3.45-fold; $p=0.0026)$ and "oxidoreductase" (2.63-fold; $p=0.0263)$.

We found 1,207 genes that were at least twofold more highly expressed in the brain of the ferret (Additional file 5: Table S4). In the domain "molecular function", the GO terms "catalytic activity" (374) and "binding" (351) were the highest. Among the GO-Slim terms that showed significant enrichment were "structural constituent of ribosome" (>5fold; $p=1.9 \times 10^{-22}$ ), "translation initiation factor activity" (2.92-fold; $p=0.038$ ) and "oxidoreductase activity" (1.84fold; $p=0.00057)$. In the domain "biological process", the highest numbers were allocated to the GO terms "metabolic process" (115) and "cellular process" (101). In the domain "protein class", the highest numbers were found in the terms "nucleic acid binding" (181), "enzyme modulator" (86) and "transferase" (83). The Overrepresentation Test showed significant enrichment of the terms, among others, test were "oxidative phosphorylation" (4.74-fold; $p=0.000265)$, "respiratory electron transport chain" (2.68-fold; $p=0.000128)$ and "translation" (3.66-fold; $\left.p=8.77 \times 10^{-23}\right)$.

Comparative analysis of mammalian brain transcriptomes The high expression of CLU and S100B in the visual cortex of the hooded seal compared to the ferret cortex was verified by qRT-PCR (Additional file 6: Figure S1). To evaluate the expression levels of CLU and S100B in the brain of other mammals, we obtained the brain transcriptomes of other mammals from the SRA database (Additional file 7: Spreadsheet S2). If available, we selected transcriptomes from the cerebral cortex. For the whale species, only a "brain" transcriptome (without further specification) from the minke whale and a cerebellum transcriptome from the bowhead whale were available. We found high expression of CLU only in the brain transcriptome of the hooded seal but not in any other of the investigated mammalian brain transcriptomes (Fig. 2a). S100B was found to be highly expressed in the hooded seal as well as in the two whale brains. The S100B expression levels were statistically different between diving and non-diving species (two-tailed $t$-test; $p=0.0009$ ).

As the neuron/glia ratio may differ between the brain samples and whales may have a higher relative content of glia cells [30], we normalised the S100B expression rates according to the relative expression levels of a neuronal marker (RBFOX3) and a glial marker gene (GFAP) (note: CLU was not normalised because it is expressed in both neurons and glia cells). In fact, the GFAP/RBFOX3 ratios vary between the species up to a factor of $>200$ (Fig. 2b). However, the normalised expression ratios clearly show significantly higher levels of S100B in the brains of the hooded seal and the two whale species $(p=0.0021)$.

To evaluate the similarities of the brain transcriptomes between different species, correlation coefficients of the transcriptomes were calculated and visualised by a neighborjoining tree (Additional file 8: Figure S2). No general similarity of the brain transcriptomes of the diving mammals was found. The whale brain transcriptomes cluster with that of the cow and the transcriptomes from the visual cortex of the hooded seal with that of the ferret, probably reflecting the evolutionary relationships of the taxa.

\section{Discussion}

No indication of higher anaerobic capacity of the seal brain, but evidence for reduced aerobic energy metabolism

At least during long dives, the brain of whales and seals must cope with a reduced supply of oxygen. While the 

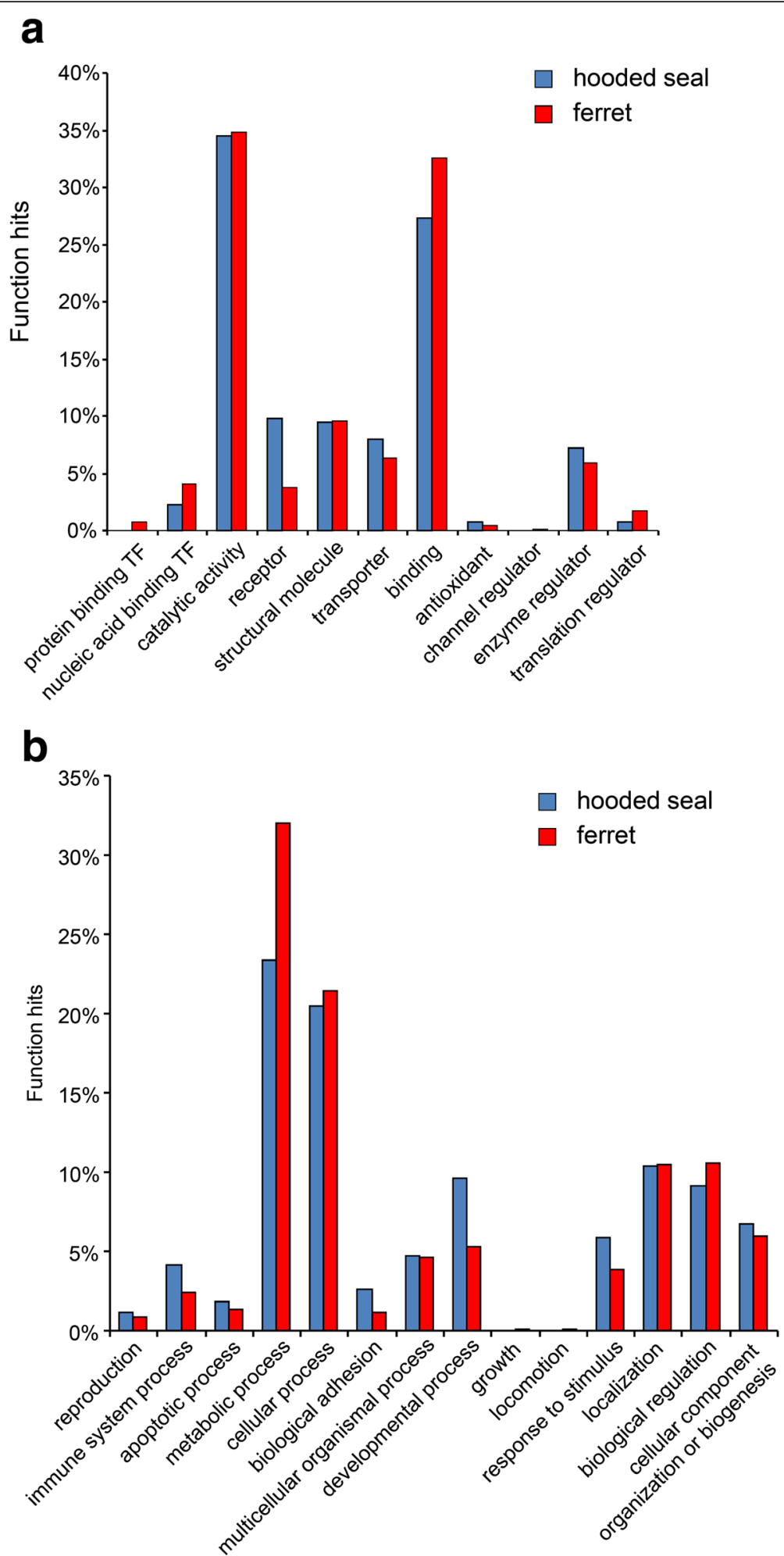

Fig. 1 Gene ontology (GO) analyses of the differentially expressed genes in the seal (blue) and ferret (red). Only genes with an at least twofold difference in expression levels and RPKM $>5$ in both species were considered. a GO terms in the PANTHER Annotation Data Set "Molecular Function". b GO terms in the PANTHER Annotation Data Set "Biological Process" 

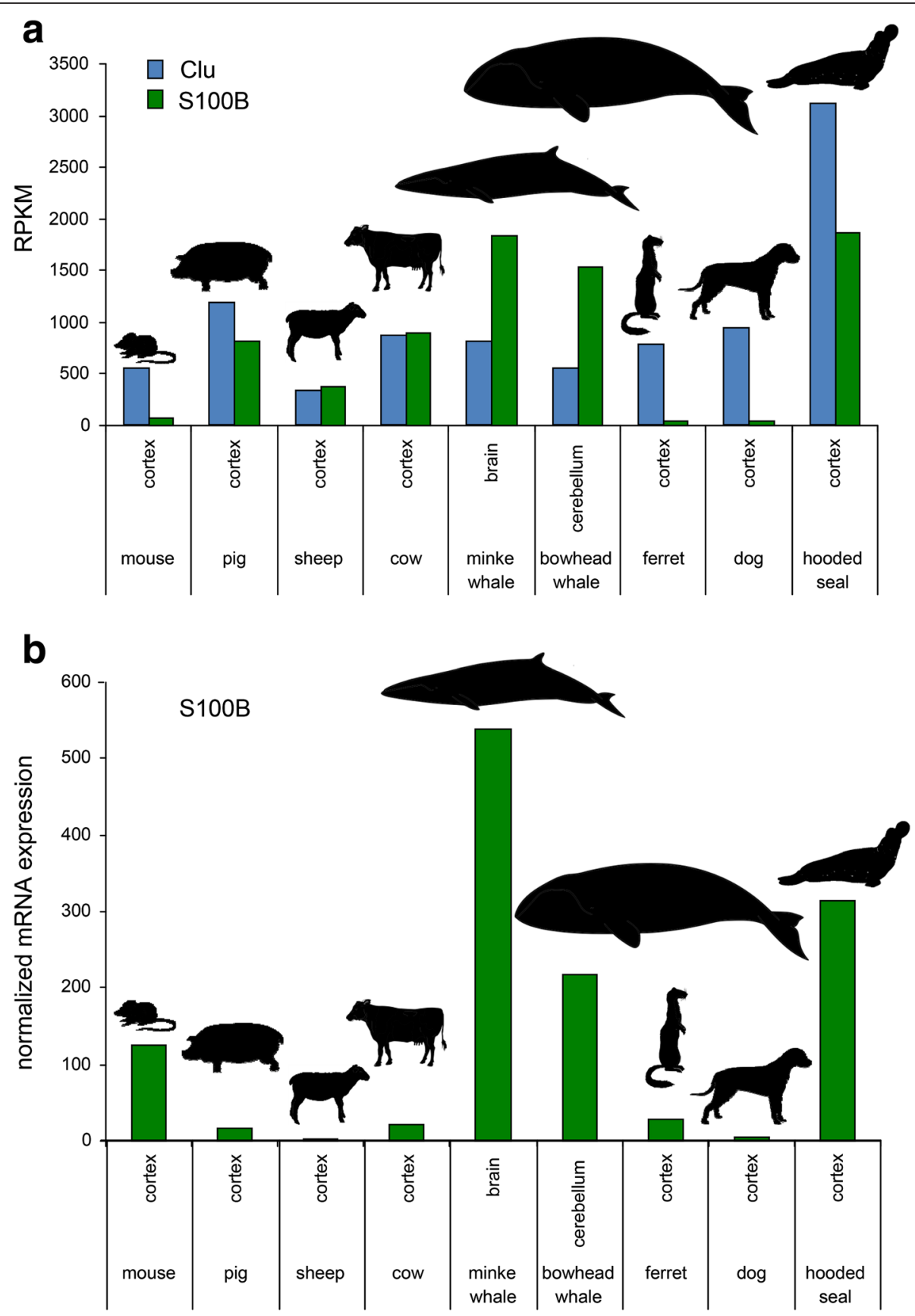

Fig. 2 Expression levels of $\mathrm{Clu}$ (blue) and S100B (green) in brain tissues of diving and non-diving mammals a The specific brain regions and the species are indicated. $\mathbf{b}$ S100B expression was normalised according to the neuron/glia ratio

systemic mechanisms that help diving mammals to survive are well studied on the level of the organism [7-10, $13-15,17,28,29]$, little is known about the molecular mechanisms that help the brain tolerate periods of hypoxia. Notably, the mRNA levels of the key enzymes for anaerobic metabolism, lactate dehydrogenase $\mathrm{A}$ and $\mathrm{B}$ (LDHA and LDHB), are lower in the visual cortex of the hooded seal than in the ferret (Additional file 3:
Spreadsheet S1), confirming qRT-PCR studies and activity tests [31]. Thus, despite the ability of the seal neurons to tolerate extended periods of hypoxia [23-25] and high reported seal brain glycogen levels $[6,25,32]$, there is - at least at the transcriptome level - no evidence for a higher anaerobic capacity of the total brain. Rather there appears to exist an adjustment of the labour division between neurons and astrocytes, resulting e.g. in a higher anaerobic 
capacity of neurons and a higher aerobic metabolism of astrocytes, which may improve neuronal survival [26, 27, 31].

Analysis of the GO terms showed that a large fraction of the genes that are significantly overrepresented in the ferret brain transcriptome are related to the aerobic energy metabolism (e.g., "oxidative phosphorylation", "respiratory electron transport chain", "generation of precursor metabolites and energy") (Additional file 5: Table S4). This is not the case in the seal brain. Thus, rather than having a higher anaerobic capacity, as observed in other hypoxia or anoxia-tolerant species [10, 33, 34], the adaptation of the seal brain to low oxygen conditions may involve a lower aerobic energy metabolism. We also found in the overrepresented ferret genes the enriched GO terms related to translation, which also suggests comparably lower protein synthesis in the seal brain. Because translation is one of the most ATP-demanding cellular processes, its reduction may also contribute to a global energy saving of the seal brain. Similar observations have been made before, e.g. in fish exposed to hypoxia or in anoxic turtles [33, 35, 36].

We further note that we found no evidence that the observed expression patterns are markedly influenced by the use of specific brain areas, sex, or morphological factors like brain or body masses. Correlation analyses of gene expression between the mammalian brain transcriptomes showed a remarkable correlation between gene expression patterns and species phylogeny (Additional file 8: Figure S2). Thus, the phylogenetic relationship appears to be the main driving force of gene expression in the brain, thereby justifying the use of the ferret as close relative for a comparison with the seal.

\section{Clusterin and S100B may contribute to stress tolerance of the diving brain}

CLU (also known as apolipoprotein J) is the most highly expressed gene in the visual cortex of the hooded seal (3104.4 RPKM). The RPKM is much higher than in the visual cortex of the ferret or in other publically available transcriptomes of other mammals (Fig. 2a), suggesting a specific adaptation of the hooded seal brain. The $C L U$ gene codes for two distinct products that exert multiple functions [37, 38]. The conventional, secreted form is a heterodimeric glycoprotein that acts as an extracellular chaperone, and it is thought to promote cellular survival. Alternative splicing results in a truncated CLU protein, which interferes with the BAX-mediated apoptosis pathway. In humans, CLU is involved in several neurodegenerative diseases [38]. For example, soluble CLU prevents the aggregation of amyloid $\beta$ protein in Alzheimer's disease [39] and high levels of CLU mRNA have been associated with aging [40]. Upregulation of CLU has been observed under various stress conditions, including oxidative stress [38]. It is thus conceivable that $C L U$ protects the seal brain from the oxidative stress brought about by the hypoxic periods of the dive as well as during reoxygenation when the seal surfaces. In this context, the high levels of Clu mRNA in the seal brain may either be interpreted as a pre-adaptation to the stress conditions during the dives, or Clu expression was induced by the stress conditions during the dives.

The largest difference in expression was found for S100B, which has 38 -fold higher RPKM in the hooded seal cortex compared to the ferret cortex (1860.3 vs. 49.0 RPKM). S100B is an EF-hand, $\mathrm{Ca}^{2+}$-binding protein that is, at least in the brains of mouse, rat and man, mainly expressed in astrocytes but also in certain neurons [41-43]. We must note that we have no information on the cellular distribution of S100B in the hooded seal, ferret and most other species used in the comparative approach. S100B has intracellular and extracellular functions, and regulates a variety of processes, including cell proliferation, activation of astrocytes during brain damage and disease, as well as promoting cancer. In humans, high levels of S100B have been associated with schizophrenia [44, 45] and other brainrelated diseases $[46,47]$. Notably, S100B was also found elevated in the brains of the minke and the bowhead whales compared to the brains of non-diving mammals (Fig. 2a), and this difference remains when the RPKM values were corrected according to the glia/neuron ratio (Fig. 2b). Cluster analyses of the correlation coefficients of the expression values of the different transcriptomes exclude that the observed similarities are due to similar brain regions (Additional file 8: Figure S2). Thus, S100B is component of a common stress adaptation mechanism, which must have evolved convergently in whales and seals, and which helps the brain of diving mammals to survive better a reduced oxygen supply. One possible mechanism may be that the high S100B levels enhance the intracellular $\mathrm{Ca}^{2+}$ binding sites, thus increasing the $\mathrm{Ca}^{2+}$ buffering capacity and thereby reduce hypoxia-induced excitotoxicity, as the massive influx of $\mathrm{Ca}^{2+}$ would otherwise cause irreversible neuronal damages and induces apoptosis [3-5]. Alternatively, the high levels of S100B may be an indicator of the brain damage that occurs in response to the stressful life of diving mammals.

Multiple other genes showed remarkable differences in expression levels, but their functions in the brain are more difficult to interpret. For example, previous studies have associated OGN with bone and muscle formation [48] and CYP4V2 is associated in man with retinal dystrophy [49]. However, the 10.1 times higher seal levels of NEIL2, a glycosylase associated with the repair of DNA $[50,51]$, may be easily explained by increased DNA damage in the hypoxic seal brain. PON2, which metabolizes oxidized arachidonic acid and docosahexaenoic acid [52], is 5.54 times higher in the hooded seal and may be involved in the antioxidative response of the brain cells. However, as for $\mathrm{Clu}$ and S100B, it remains unclear, whether genes that were highly expressed in the seal 
brain reflect an intrinsic feature, or whether these increased in response to the stress evoked by the dives.

\section{Conclusions}

Each year, millions of individuals die or become morbidly ill because of conditions or diseases that reduce oxygen-supply to hypoxia-sensitive tissues such as the brain. Acute metabolic insults like stroke have an especially devastating impact which is mostly impossible to repair. By contrast, brains of diving mammals tolerate extended periods of systemic hypoxia. Differential regulation of specific genes, such as $C L U$ and $S 100 B$, but probably also many others, may be instrumental in the protection of the diving brain. These genes may also be suitable drug targets for drugs that prevent e.g. stroke.

\section{Methods}

\section{Animals and sample preparation}

Adult hooded seals $(n=5$; female, body mass 142 to $220 \mathrm{~kg}$ ) were captured in the pack ice of the Greenland Sea, and were euthanised under deep gas anesthesia (ventilation with 1.5-3 \% isoflurane [Forene, Abbott, Germany] in air), after initial sedation (intramuscular or intravenous injection of $1.5-3.0 \mathrm{mg}$ zolazepam/tiletamine per $\mathrm{kg}$ of body mass). After bleeding and decapitation, brain samples were preserved frozen at $-80{ }^{\circ} \mathrm{C}$ in RNAlater (Qiagen, Hilden, Germany). Four adult ferrets (M. putorius furo) (male; $\sim 2$ years old; body mass $\sim 1.5 \mathrm{~kg}$ ) were obtained from the animal facilities of the University Medical Center Hamburg-Eppendorf (UKE, Germany). The animals were killed in deep anesthesia (Ketamin/ Domitor), with an overdose of pentobarbital; subsequently the brain was removed by the veterinarians. Brain samples were preserved at $-80{ }^{\circ} \mathrm{C}$ in RNAlater.

Total RNA was extracted using peqGOLD Trifast (PEQLAB, Erlangen, Germany) in association with Crystal RNA Mini Kit (Biolab Products, Bebensee, Germany). After quantity and quality analysis using spectrophotometry and gel electrophoresis, RNA samples were used for Illumina sequencing or qRT-PCR.

\section{Sequencing and assembly of the transcriptomes}

A library for paired-end sequencing of 300 nt was generated from $5 \mu \mathrm{g}$ RNA from the hooded seal visual cortex (adult female). Sequencing was performed with the MiSeq chemistry v3 with an estimated output of 50 million reads (StarSEQ, Mainz, Germany). For the ferret (adult male), a library for paired-end sequencing of $125 \mathrm{nt}$ was generated from $1 \mu \mathrm{g}$ RNA of the visual cortex and sequencing was performed with the HiSeq2500 chemistry v4 with an estimated output of 25 million reads (GATC Biotech, Konstanz, Germany). Sequence quality analyses were performed via FastQC and CLC-Genomics Workbench (version 7.5). For trimming, all reads with more than two ambiguous characters and with a mean Phred quality of below 15 were discarded. Additionally, the first 14 nucleotides from the $5^{\prime}$ end were trimmed.

For de novo assembly of the brain transcriptome of the hooded seal, the quality controlled paired-end reads $(12,473,522$ reads) were used. After assembly, a backmapping step of the reads was performed. Only contigs with a minimum length of $300 \mathrm{bp}$ were accepted for BLAST analysis. The de novo assembly and backmapping were performed with CLC-Genomics Workbench (version 7.5).

The raw Illumina files of the transcriptomes from the visual cortex of the hooded seal and the ferret are available from the NCBI SRA database under the accession numbers SRR3001184 (Bioproject PRJNA278355) and SRR3000035 (PRJNA305974), respectively.

\section{Functional transcriptome annotation}

To annotate the de novo contigs of the transcriptome of the brain of the hooded seal, a local BLAST search was performed with the BLAST tool of the CLC workbench. Two different protein databases were used to annotate the contigs; firstly, the curated and non-redundant SWISSPROT database and secondly only the human RefSeq protein database (for consequent Gene Ontology (GO) annotation). Only BLAST hits with an expectation value of $\mathrm{E}<10^{-5}$ were accepted. We preferentially annotated ambiguous contigs based on the similarity to walrus (Odobenus rosmarus) and ferret ( $M$. putorius furo) genes.

To identify overrepresented functional categories among different sets of expressed genes, we used PANTHER (Protein ANalysis THrough Evolutionary Relationships; http:// go.pantherdb.org/) Version 10.0 [53]. The GO terms in the domains "molecular function" and "biological process", and the protein class were reported. Enrichment of categories was evaluated using the PANTHER Overrepresentation Test (release 2015.04.30) using the human genes as reference list. The complete GO terms and PANTHER GOSlim terms were tested. Categories with $p$-values $<0.05$ after Bonferroni correction were considered significant.

\section{Expression analysis (RNA-seq)}

Mapping was performed using the RNA-seq algorithm of the CLC-Genomics Workbench (version 7.5). The ferret Ensembl-build 1.0.75 was used as reference genome. The trimmed seal reads were mapped using the following parameters: $75 \%$ of the read length and $75 \%$ of the nucleotides were required to match the reference for the read to be included in the mapping. The paired read distance was calculated automatically ranging from 145 to 730 bp. Only reads mapping uniquely in the genome were used for RPKM calculation eliminating repetitive sequence bias in read quantification. For the trimmed ferret RNA-seq dataset the parameters were adjusted to $95 \%$ similarity and $95 \%$ length match, for a read to be 
included in the mapping. The paired read distance was calculated automatically ranging from 90 to $378 \mathrm{bp}$.

\section{Comparative transcriptomics}

We retrieved the publicly available transcriptomes of mouse (Mus musculus) cortex, pig (Sus scrofa) cortex, dog (Canis lupus familiaris) cortex, cow (Bos taurus) cortex, sheep (Ovis aries) cortex, minke whale (Balaenoptera acutorostrata) brain, and bowhead whale (Balaena mysticetus) cerebellum from the SRA database (accession numbers SRX186042, ERX240895, ERX324009, SRX211675, ERX 454974, SRX313597, and SRX790347). Each dataset was mapped to the appropriate genome (whale transcriptomes were mapped against the Bos taurus genome), and gene expression was calculated as RPKM (Reads Per Kilobase per Million mapped reads). Only genes with RPKM $\geq 5$ in the hooded seal were included. Statistical evaluation was performed with GraphPad Prism 6, version 6.01 (La Jolla California USA).

To correct for the different species or brain regions, the glia/neuron ratio of each sample was calculated using the RPKM values of GFAP and RBFOX3 (alias $\mathrm{NeuN}$ ) as a proxy. Because RBFOX3 is currently not annotated in the pig genome, we used SNAP25 as neuronal gene to calculate the glia/neuron ratio in this species. Correlation analysis was done employing the corrected values. The Pearson correlation coefficients were calculated using Microsoft Excel 2013 on 4650 corrected gene expression values. The correlation coefficients of gene expression between species were converted into distances and used to calculate a tree employing the NEIGHBOR program of the PHYLIP 3.68 package.

\section{Quantitative real-time RT-PCR}

First-strand cDNA was synthesised from $1.5 \mu \mathrm{g}$ total RNA of cortex samples of hooded seal and ferret using the Fermentas RevertAid $\mathrm{H}^{-}$Reverse Transcriptase Kit (Thermo Fisher Scientific, Braunschweig, Germany) according to manufacturer's instructions. qRT-PCR was performed on the ABI 7500 real-time PCR system with the Power SYBR Green master mix (Applied Biosystems, Darmstadt, Germany) using a 40 cycles protocol $\left(95^{\circ} \mathrm{C}\right.$ for $15 \mathrm{~s}, 60^{\circ} \mathrm{C}$ for $15 \mathrm{~s}, 72{ }^{\circ} \mathrm{C}$ for $30 \mathrm{~s}$ ). Primer sequences are given in Additional file 9: Table S5. The relative mRNA levels were calculated using the cycle threshold (CT) values and were reported as fold changes of the ferret mRNA levels.

\section{Additional files}

Additional file 1: Table S1. Summary of Illumina sequencing. The numbers of reads before and after quality trimming are given. The percentage of reads mapped to the ferret genome is denoted. (PDF $20 \mathrm{~kb}$ )

Additional file 2: Table S2. De novo assembly of the transcriptome from the seal visual cortex. (PDF 6 kb)
Additional file 3: Spreadsheet S1. Comparative gene expression in the seal and ferret brain. Gene expression (RPKM values) in the visual cortex of the hooded seal and the ferret. The cut-off was set to RPKM $>5$ in both species. (XLSX $406 \mathrm{~kb}$ )

Additional file 4: Table S3. Genes overrepresented in the seal brain. Ontology analysis of genes that are at least twofold higher expressed in the visual cortex of the hooded seal compared to the ferret visual cortex. A. The GO terms for the domains "molecular function" and "biological process", and the "protein class" are given. B and C. PANTHER

Overrepresentation Test of the domains "molecular function", "biological process", and "protein class" using the complete (B) and PANTHER GO-slim terms. (PDF 24 kb)

Additional file 5: Table S4. Genes overrepresented in the ferret brain. Ontology analysis of genes that are at least twofold higher expressed in the visual cortex of the ferret compared to the hooded seal visual cortex. A. The GO terms for the domains "molecular function" and "biological process", and the "protein class" are given. B and C. PANTHER Overrepresentation Test of the domains "molecular function", "biological process", and "protein class" using the complete (B) and PANTHER GO-slim terms. (PDF $74 \mathrm{~kb}$ )

Additional file 6: Figure S1. Comparison of qRT-PCR and RNA-seq results. The changes in selected mRNA levels in visual cortices of the hooded seal and the ferret were estimated by qRT-PCR (black; $n=4)$ and RNA-seq (white). The mRNA levels of the genes S100B, Clu, SLC1A6 and GAPDH were evaluated. Both methods gave similar results. (PDF $22 \mathrm{~kb}$ )

Additional file 7: Spreadsheet S2. Gene expression in the mammalian brain. The RPKM values have been calculated for cortices of mouse, pig, dog, cow, sheep, ferret and hooded seal, in the brain of minke whale and the cerebellum of bowhead whale. n.a., not available; n.d., not detected. (XLSX 760 kb)

Additional file 8: Figure S2. Correlation of gene expression between mammalian brain transcriptomes. The correlation coefficients were converted into distances and visualised by a neighbor-joining tree. (PDF 27 kb)

Additional file 9: Table S5. List of primers. Forward and reverse primers, which had been generated according to the conserved sequences of the ferret and hooded seal genes, used in qRT-PCR expression analyses. (PDF $6 \mathrm{~kb}$ )

\section{Abbreviations}

GO, gene ontology; qRT-PCR, quantitative real-time RT-PCR; RNA-seq, RNA Sequencing; RPKM, reads per kilobase per million mapped reads

\section{Acknowledgments}

We thank Nicole U. Czech-Damal for her help in the early phase of these studies.

\section{Funding}

This work has been supported by the Deutsche Forschungsgemeinschaft (Bu956/12). MLMH is supported by a fellowship for Ph.D. by the German Academic Exchange Service (DAAD) and Coordenação de Aperfeiçoamento de Pessoal de Nível Superior (CAPES)/Brazil (5125/11-1).

\section{Availability of data and material}

The raw Illumina files of the transcriptomes from the visual cortex of the hooded seal and the ferret are available in the NCBI SRA database (http:// www.ncbi.nlm.nih.gov/sra/) under the accession numbers SRR3001184 (Bioproject PRJNA278355) and SRR3000035 (PRJNA305974), respectively. The other mammalian brain transcriptomes were retrieved from the NCBI SRA database (accession numbers SRX186042, ERX240895, ERX324009, SRX211675, ERX454974, SRX313597, SRX790347). All other data generated or analysed during this study are included in this published article.

\section{Authors' contributions}

Conception and design of the experiments: TB. Performed research: AF, MLMH, GE, LPF. Analysis and interpretation of data: AF, MLMH, LPF, TB. Wrote the paper: $A F, M L M H, G E, L P F, T B$. All authors read and approved the final manuscript.

\section{Competing interests}

The authors declare that they have no competing interests. 


\section{Consent for publication}

Not applicable.

\section{Ethics approval and consent to participate}

Hooded seals were captured in the pack ice of the Greenland Sea with appropriate permits from Danish and Greenland Authorities, and from the National Animal Research Authority of Norway (NARA; permits no. 5399 and 7247). Seals were handled according to the EU Directive 2010/63/EU (see DIRECTIVE 2010/63/EU Annex IV, point 1a), using procedures that were approved by the NARA (permits no. 5399 and 7247) and by the authorities at the University of Tromsø (permit number AAB/06). Ferrets were handled in accordance with the German Animal Welfare act (Tierschutzgesetz) and the European guidelines for care and use of animals in scientific experiments (Directive 2010/63/EU), as approved by the Hamburg state authority for animal welfare (BUG-Hamburg, Germany; permit no. ORG719).

\section{Author details}

${ }^{1}$ Institute of Zoology, Biocenter Grindel, University of Hamburg,

Martin-Luther-King-Platz 3, D-20146 Hamburg, Germany. ${ }^{2}$ Department of Neurophysiology and Pathophysiology, University Medical Center Hamburg-Eppendorf, 20246 Hamburg, Germany. ${ }^{3}$ Department of Arctic and Marine Biology, University of Tromsø - The Arctic University of Norway, NO-9037 Tromsø, Norway.

\section{Received: 19 March 2016 Accepted: 6 July 2016 Published online: 09 August 2016}

\section{References}

1. Peers C, Pearson HA, Boyle JP. Hypoxia and Alzheimer's disease. Essays Biochem. 2007;43:153-64.

2. Speer RE, Karuppagounder SS, Basso M, Sleiman SF, Kumar A, Brand D, Smirnova N, Gazaryan I, Khim SJ, Ratan RR. Hypoxia-inducible factor prolyl hydroxylases as targets for neuroprotection by "antioxidant" metal chelators: From ferroptosis to stroke. Free Radic Biol Med. 2013;62:26-36.

3. Dirnagl U, ladecola C, Moskowitz MA. Pathobiology of ischaemic stroke: an integrated view. Trends Neurosci. 1999;22(9):391-7.

4. Haddad $G G$, Jiang $\mathrm{C}_{\text {. }} \mathrm{O}_{2}$ deprivation in the central nervous system: on mechanisms of neuronal response, differential sensitivity and injury. Prog Neurobiol. 1993:40(3):277-318.

5. Hansen AJ. Effect of anoxia on ion distribution in the brain. Physiol Rev. 1985;65(1):101-48.

6. Kerem D, Elsner R. Cerebral tolerance to asphyxial hypoxia in the harbor seal. Respir Physiol. 1973;19(2):188-200.

7. Butler PJ. Metabolic regulation in diving birds and mammals. Respir Physiol Neurobiol. 2004;141(3):297-315.

8. Butler PJ, Jones DR. Physiology of diving of birds and mammals. Physiol Rev. 1997;77(3):837-99.

9. Ramirez JM, Folkow LP, Blix AS. Hypoxia tolerance in mammals and birds: from the wilderness to the clinic. Annu Rev Physiol. 2007;69:113-43.

10. Larson J, Drew KL, Folkow LP, Milton SL, Park TJ. No oxygen? No problem! Intrinsic brain tolerance to hypoxia in vertebrates. J Exp Biol. 2014;217(Pt 7): 1024-39.

11. Folkow LP, Blix AS. Air breathers under water: diving mammals and birds. In: Nilsson GE, editor. Respiratory physiology of vertebrates Life with and without oxygen. Cambridge: Cambridge University Press; 2010. p. 222-64.

12. Meir JU, Champagne CD, Costa DP, Williams CL, Ponganis PJ. Extreme hypoxemic tolerance and blood oxygen depletion in diving elephant seals. Am J Physiol Regul Integr Comp Physiol. 2009;297(4):R927-939.

13. Davis RW. A review of the multi-level adaptations for maximizing aerobic dive duration in marine mammals: from biochemistry to behavior. J Comp Physiol B. 2014;184(1):23-53.

14. Blix AS, Folkow B. Cardiovascular adjustments to diving in mammals and birds. In: Sheperd JT, Abboud FM, editors. Handbook of Physiology-The Cardiovascular System III. Bethesda: Am. Physiol. Soc; 1983. p. 917-45.

15. Ponganis PJ. Diving Mammals. Comp Physiol. 2011;1(1):447-65.

16. Williams TM, Zavanelli M, Miller MA, Goldbeck RA, Morledge M, Casper D, Pabst DA, McLellan W, Cantin LP, Kliger DS. Running, swimming and diving modifies neuroprotecting globins in the mammalian brain. Proc R Soc Lond Ser B Biol Sci. 2008;275(1636):751-8.

17. Scholander PF. Experimantal investigations on the respiratory function in diving mammals and birds. Hvalradets Skr. 1940;22:1-131.
18. Blix AS, Elsner R, Kjekshus JK. Cardiac output and its distribution through capillaries and A-V shunts in diving seals. Acta Physiol Scand. 1983;118(2):109-16.

19. Kooyman GL, Castellini MA, Davis RW. Physiology of diving in marine mammals. Annu Rev Physiol. 1981;43:343-56.

20. Ortiz RM. Osmoregulation in marine mammals. J Exp Biol. 2001;204(Pt 11):1831-44.

21. Folkow LP, Blix AS. Diving behaviour of hooded seals (Cystophora cristata) in the Greenland and Norwegian Seas. Polar Biol. 1999;22(1):61-74.

22. Qvist J, Hill RD, Schneider RC, Falke KJ, Liggins GC, Guppy M, Elliot RL, Hochachka PW, Zapol WM. Hemoglobin concentrations and blood gas tensions of free-diving Weddell seals. J Appl Physiol. 1986;61(4):1560-9.

23. Folkow LP, Ramirez JM, Ludvigsen S, Ramirez N, Blix AS. Remarkable neuronal hypoxia tolerance in the deep-diving adult hooded seal (Cystophora cristata). Neurosci Lett. 2008;446(2-3):147-50.

24. Ramirez JM, Folkow LP, Ludvigsen S, Ramirez PN, Blix AS. Slow intrinsic oscillations in thick neocortical slices of hypoxia tolerant deep diving seals. Neuroscience. 2011;177:35-42.

25. Czech-Damal NU, Geiseler SJ, Hoff ML, Schliep R, Ramirez JM, Folkow LP, Burmester $\mathrm{T}$. The role of glycogen, glucose and lactate in neuronal activity during hypoxia in the hooded seal (Cystophora cristata) brain. Neuroscience. 2014;275:374-83.

26. Mitz SA, Reuss S, Folkow LP, Blix AS, Ramirez JM, Hankeln T, Burmester T. When the brain goes diving: glial oxidative metabolism may confer hypoxia tolerance to the seal brain. Neuroscience. 2009;163(2):552-60.

27. Schneuer M, Flachsbarth S, Czech-Damal NU, Folkow LP, Siebert U, Burmester T. Neuroglobin of seals and whales: evidence for a divergent role in the diving brain. Neuroscience. 2012;223:35-44.

28. Yim HS, Cho YS, Guang X, Kang SG, Jeong JY, Cha SS, Oh HM, Lee JH, Yang EC, Kwon KK, et al. Minke whale genome and aquatic adaptation in cetaceans. Nat Genet. 2014;46(1):88-92.

29. Foote AD, Liu Y, Thomas GW, Vinar T, Alfoldi J, Deng J, Dugan S, Van Elk CE, Hunter ME, Joshi $V$, et al. Convergent evolution of the genomes of marine mammals. Nat Genet. 2015;47(3):272-5.

30. Manger PR. An examination of cetacean brain structure with a novel hypothesis correlating thermogenesis to the evolution of a big brain. Biol Rev Camb Philos Soc. 2006;81(2):293-338.

31. Hoff MLM, Fabrizius A, Folkow LP, Burmester T. An atypical distribution of lactate dehydrogenase isoenzymes in the hooded seal (Cystophora cristata) brain may reflect a biochemical adaptation to diving. J Comp Physiol B. 2016;469(3):275-80.

32. Kerem D, Hammond DD, Elsner R. Tissue glycogen levels in the Weddell seal, Leptonychotes weddelli: a possible adaptation to asphyxial hypoxia. Comp Biochem Physiol A Comp Physiol. 1973;45(3):731-6.

33. Hochachka PW, Buck LT, Doll CJ, Land SC. Unifying theory of hypoxia tolerance: molecular/metabolic defense and rescue mechanisms for surviving oxygen lack. Proc Natl Acad Sci U S A. 1996;93(18):9493-8.

34. Lutz PL, Nilsson GE. Vertebrate brains at the pilot light. Respir Physiol Neurobiol. 2004;141(3):285-96.

35. Van Ginneken VJT, Van Caubergh P, Nieveen M, Balm P, Van Den Thillart G, Addink A. Influence of hypoxia exposure on the energy metabolism of common carp (Cyprinus Carpio L.). Neth J Zool. 1997;48(1):65-82.

36. Fraser KP, Houlihan DF, Lutz PL, Leone-Kabler S, Manuel L, Brechin JG. Complete suppression of protein synthesis during anoxia with no postanoxia protein synthesis debt in the red-eared slider turtle Trachemys scripta elegans. J Exp Biol. 2001;204(Pt 24):4353-60.

37. Park S, Mathis KW, Lee IK. The physiological roles of apolipoprotein J/ clusterin in metabolic and cardiovascular diseases. Rev Endocr Metab Disord. 2014;15(1):45-53.

38. Pucci S, Mazzarelli P, Missiroli F, Regine F, Ricci F. Neuroprotection: VEGF, IL6, and clusterin: the dark side of the moon. Prog Brain Res. 2008;173:555-73.

39. Giannakopoulos P, Kovari E, French LE, Viard I, Hof PR, Bouras C. Possible neuroprotective role of clusterin in Alzheimer's disease: a quantitative immunocytochemical study. Acta Neuropathol. 1998;95(4):387-94.

40. Trougakos IP, Gonos ES. Clusterin/apolipoprotein J in human aging and cancer. Int J Biochem Cell Biol. 2002;34(11):1430-48.

41. Donato R, Sorci G, Riuzzi F, Arcuri C, Bianchi R, Brozzi F, Tubaro C, Giambanco I. S100B's double life: intracellular regulator and extracellular signal. Biochim Biophys Acta. 2009;1793(6):1008-22.

42. Heizmann CW, Fritz G, Schafer BW. S100 proteins: structure, functions and pathology. Front Biosci. 2002;7:d1356-1368.

43. Donato R, Cannon BR, Sorci G, Riuzzi F, Hsu K, Weber DJ, Geczy CL. Functions of S100 proteins. Curr Mol Med. 2013;13(1):24-57. 
44. Yelmo-Cruz S, Morera-Fumero AL, Abreu-Gonzalez P. S100B and schizophrenia. Psychiatry Clin Neurosci. 2013;67(2):67-75.

45. Aleksovska K, Leoncini E, Bonassi S, Cesario A, Boccia S, Frustaci A. Systematic review and meta-analysis of circulating S100B blood levels in schizophrenia. PLoS ONE. 2014;9(9), e106342.

46. Kalia M, Costa ESJ. Biomarkers of psychiatric diseases: current status and future prospects. Metabolism. 2015;64(3 Suppl 1):S11-15.

47. Rohlwink UK, Figaji AA. Biomarkers of brain injury in cerebral infections. Clin Chem. 2014;60(6):823-34.

48. Tanaka K, Matsumoto E, Higashimaki Y, Katagiri T, Sugimoto T, Seino S, Kaji $\mathrm{H}$. Role of osteoglycin in the linkage between muscle and bone. J Biol Chem. 2012;287(15):11616-28.

49. Li A, Jiao X, Munier FL, Schorderet DF, Yao W, Iwata F, Hayakawa M, Kanai A, Chen MS, Lewis RA, et al. Bietti crystalline corneoretinal dystrophy is caused by mutations in the novel gene CYP4V2. Am J Hum Genet. 2004;74(5):817-26.

50. Hazra TK, Kow YW, Hatahet Z, Imhoff B, Boldogh I, Mokkapati SK, Mitra S, Izumi T. Identification and characterization of a novel human DNA glycosylase for repair of cytosine-derived lesions. J Biol Chem. 2002;277(34): 30417-20.

51. Dou H, Mitra S, Hazra TK. Repair of oxidized bases in DNA bubble structures by human DNA glycosylases NEIL1 and NEIL2. J Biol Chem. 2003;278(50): 49679-84.

52. Draganov DI, Teiber JF, Speelman A, Osawa Y, Sunahara R, La Du BN. Human paraoxonases (PON1, PON2, and PON3) are lactonases with overlapping and distinct substrate specificities. J Lipid Res. 2005;46(6):1239-47.

53. Mi HY, Muruganujan A, Casagrande JT, Thomas PD. Large-scale gene function analysis with the PANTHER classification system. Nat Protoc. 2013; 8(8):1551-66.

\section{Submit your next manuscript to BioMed Central} and we will help you at every step:

- We accept pre-submission inquiries

- Our selector tool helps you to find the most relevant journal

- We provide round the clock customer support

- Convenient online submission

- Thorough peer review

- Inclusion in PubMed and all major indexing services

- Maximum visibility for your research

Submit your manuscript at www.biomedcentral.com/submit 